\title{
Impact of Ozone on the Growth and Yield of Trees: A Review
}

\author{
JOHN M. PYE*
}

\begin{abstract}
Data from 25 experiments on seedlings of 43 tree species and hybrids show that ozone $(0$,$) can reduce growth and photosynthesis at con-$ centrations common in many areas of the USA. Seedlings have been primarily employed for such studies for logistic reasons, and will likely provide the greatest breadth of information for some time to come. However, a number of impediments limit application of seedling response studies to assessment of impacts on regional timber production. Large trees differ from seedlings in a number of ways, including C allocation and canopy structure, and methods must be developed to account for these differences if information from seedling studies is to prove useful to forest impact assessment. Understanding how competition mediates individual Iree responses will require investigation of whether systematic differences of microclimate leaf morphology that exist across canopies affects foliage sensitivity to $\mathrm{O}_{3}$, and whether the maximum growth rates of genotypes are correlated with susceptibility 100 . Definitive information on these factors is necessary to assess imparts of 0 , on stand development and diameter distributions in both multi- and single species stands. Of critical economic importance is whether 0 , preferentially damages taller, more valuable individuals within stands and more valuable, faster growing stand types.
\end{abstract}

Of the several air pollutants common in various regions of the USA, ozone $(0$,$) is the only one likely to impact$

Pest Impact Assessment Technology Research Work Unit, USDA Forest Service, Southeastern Forest Exp. Stn., Research Triangle Park, NC 27709. Contribution of the Pest Impact Assessment Technol Res. Work Unit, USDA Forest Service, Southeastern Forest Exp. Stn. Received 13 July 1987. *Corresponding author.

Published in J. Environ. Qua). 17:347-360 (1988). large areas for which sufficient response information is available to assess exposure-response relationships. Controlled exposures of trees to $\mathrm{SO}$, or $\mathrm{NO}$, have been limited to concentrations of $0.05 \mu \mathrm{L} / \mathrm{L}$ and above, concentrations that are rare in most forested areas of the country (Altshuller, 1983; National Research Council, 1986). Additionally $\mathrm{NO}$, and $\mathrm{SO}$, are subject to relatively large spatial and temporal variability (Seinfeld, 1986; Roberts, 1984), complicating estimation of exposure for rural areas with little monitoring. Assessment of acid deposition is complicated by negative and positive impacts (Bell, 1986), unresolved mechanisms of action (Society of American Foresters, 1984), and the probable importance of indirect effects (Ulrich, 1983).

Several excellent 0 , reviews are available (Guderian, 1985; Heath, 1980; Heck et al., 1986; Mudd, 1984; Runeckles, 1986), but they have not focused on responses of tree species. Several have addressed impacts on trees but they are either theoretical syntheses or qualitative discussions of response (Winner and Atkinson, 1986; Harkov and Brennan, 1979; Taylor and Norby, 1984; Kozlowski and Constantinidou, 1986a, b). Here I review data from controlled exposures and discuss how such data might be incorporated in large-scale economic assessments.

This review consists of three parts: (i) a critique of available experimental approaches, (ii) a review of tree response data from controlled fumigations, and (iii) a discussion of difficulties extrapolating these results to regional economic damage assessments. This analysis is 
restricted to estimation of timber market impact, ignoring other benefits that forests provide.

\section{EXPERIMENTAL APPROACHES}

Fisher (1981) cites two methods for determining damage functions for polluation impact assessment: statistical field studies (e.g., Miller, 1983; Kercher and Exelrod, 1981), and controlled exposure-response experiments (as in Heck et al., 1986). Statistical field studies exploiting spatial or temperal contrasts in $\mathrm{O}_{3}$ have been made difficult by low spatial resolution and few years of comparable $\mathrm{O}_{3}$ concentration data (Pinkerton and Lefohn, 1986; USEPA, 1986). A third approach providing the most rapic input to policy makers is expert opinion, possibly structured around interdisciplinary workshops (e.g., Holling and Chambers, 1973; Bonnickson and Becker, 1983).

The most prominent model of the experimental approach to regional air pollution impact assessment is The National Crop Loss Assessment Network (NCLAN) (Heck et al., 1986), in which yield reductions were estimated from a series of exposure-response fumigation studies. However, long rotations and the large sizes of trees prevent rotation-long fumigation as employed by NCLAN, complicating estimation of stand-level yield impacts. Greater heterogeneity of soils, topography and species, and poorly characterized intraspecific variability each present additional problems for stand and regional extrapolation.

\section{Fumigation Chamber Designs}

Indoor growth chambers, greenhouses, and continuously stirred tank reactors (CSTR's) are the most common fumigation environments for tree studies. In these indoor environments, plants differ morphologically and physiologically from those grown outdoors, and they react differently to 0, (Lewis and Brennan, 1977).

Outdoor exposures usually employ open-top chambers (OTC) or, rarely, chamberless designs (Reich and Amundson, 1984). Chamberless designs produce the fewest microclimatic artifacts, particularly in winter (Olszyk et al., 1986), but control of fumigation levels under differing winds has proved difficult (Guderain et al., 1985). Open-top chambers after temperature, humidity, and air flow, extending leaf retention and increasing height growth over chamberless controls (Duchelle et al., 1982; Wang et al., 1986). Chamberless designs may benefit from improvements in airflow control, but OTC's currently provide the most realistic data on yield response.

Ideally, exposure-response studies should include treatments representing four or more concentrations of $\mathrm{O}$, that span the range of control scenarios under policy consideration, allowing nonlinear regression analysis of impacts. While unusual in tree response studies published thus far, use of this design is becoming more common.

\section{R elevant D osing Regimes}

The relevance of experimental dosing regimes depends on patterns of exposure common in forests. The most commonly cited exposure statistic is the daily 7 -hr mean, averaged over the growing season. The regional patterns of 0 , characterized by this measure obscure smaller temporal and spatial patterns. Daily 0, concentrations tend to peak around $1400 \mathrm{~h}$ near urban areas, but diurnal swings are dampened and often displaced later in the day in more remote areas (Lefohn and Jones, 1986; USEPA, 1986; Miller et al., 1982; Berry, 1964). Mean 0, concentrations in urban and rural areas are often fairly similar, about 0.040 to $0.055 \mu \mathrm{L} / \mathrm{L}$ in the southeast (Pinkerton and Lefohn, 1986). However, peak events are more extreme in cities (USEPA, 1986). In the southeast, hourly means greater than $0.120 \mu \mathrm{L} / \mathrm{L}$ occurred at only 2 of 28 rural sites, but they occurred at least once in nearly every city (Pinkerton and Lefohn, 1986).

While controlled exposure studies usually manipulate exposure means, other exposure parameters are known to affect plant response (Male; 1982). These include the variance of 0 , concentration'and the timing of episodes and respites (Jensen, 1979; Musselman et al., 1983; Hogsett et al., 1985b). Indoor fumigations usually employ square-wave dosing regimes, with constant daytime $\mathrm{O}_{3}$ concentrations. Outdoor fumigations use treatments based on fixed 0 , additions or complete removals of $\mathrm{O}_{3}$ from ambient air, resulting in realistic diurnal and seasonal variations, but with constant variance across treatments.

Most fumigations include exposure to ambient 0 , at night across ail treatments. The impact of this nighttime exposure is unknown. Although stomates are typically closed at night, Reich and Lassoie (1985) found that longterm $\mathrm{O}_{3}$ fumigation alters normal diurnal patterns of stomatal conductance, raising the possibility of significant nighttime uptake of 0 ,. Extending 0 , fumigation from 8 to $24 \mathrm{~h}$ did result in greater damage in one study (Ashmore et al., 1987, poster presented at the 19th Annual Air Pollution Workshop, Helena, MT). Note that published multiyear fumigations have also not controlled 0 , exposures during the winter months (Wang et al., 1986; Duchelle et al., 1982; Chevone et al., 1983).

There are two schools of thought on appropriate control $\mathrm{O}$, concentrations: zero and natural. Most researchers use charcoal-filtered air for their no- $\mathrm{O}_{3}$ treatment, which brings 0 , concentrations to an unspecified level near zero. This practice clarifies the mechanisms of 0 , impact and highlights impacts at low 0 , concentrations. Other researchers (e.g., Reich and Lassoie, 1985) contend that such low concentrations of 0 , do not constitute realistic controls because pristine levels of 0 , are closer to 0.025 $\mu \mathrm{L} / \mathrm{L}$ (USEAP, 1986). These researchers use control concentrations of 0.025 to $0.030 \mu \mathrm{L} / \mathrm{L}$.

\section{Types of Response M easures}

Experiments have identified biochemical and physiological effects of $\mathrm{O}_{1}$. At the biochemical level, 0, oxidizes sulfhydryl and fatty acid double bonds, increases membrane permeability, and disrupts membrane-bound photosynthetic systems (Guderian et al., 1985; Mudd, 1984). Foliar sugar and polysaccharide levels are lowered as well (Miller et al., 1969). At the physiological level, 
net photosynthesis is reduced, dark respiration is increased (Barnes, 1972), and C transport to roots is lowered (McLaughlin and McConathy, 1983). Other physiological impacts include coincident and long-term reductions in stomata1 conductance (Hill and Littlefield, 1969; Reich and Amundson, 1985; Coyne and Bingham, 1982), accelerated leaf senescence (Reich, 1983; Jensen, 1982; Noble and Jensen, 1980; Reich and Lassoie, 1985), reduced root/shoot ratio (Hogsett et al., 1985a; Chappelka and Chevone, 1986), and increased foliar leaching (Rehfuess et al., 1982).

Extrapolation to regional economic impacts requires a different set of response measures. Stand wood volume and species are important determinants of timber value. Ozone impacts on yield would occur through changes in tree regeneration, mortality, and growth rates. More will be said on stand factors in the discussion.

Wood quality is another factor affecting value. Although $\mathrm{O}_{3}$ is not thought to directly affect cambium of mature stems, it can alter wood morphology indirectly. Ozone has reduced wood density (Patton, 1981) and tracheid length (Wachsmuth et al., 1974) in controlled exposures. These changes are indicative of reductions in wood strength, pulp yield, and quality (Panshin et al., 1964).

Insect and pest interactions with 0 , are poorly understood: both increased and reduced susceptibility have been reported (Stark et al., 1968; Jeffords and Endress, 1984; Heagle, 1984). Fire damage may also be indirectly affected by 0 , through increased litterfall (Miller et al., 1982).

This review reports the three response measures most closely related to yield: dry mass increase, height growth, and net photosynthesis. A fourth measure, growth analysis, has been used by a few researchers for $\mathrm{O}_{3}$ assessment of tree species (Jensen 1981a; Jensen 1982; Jensen 1983; Chappelka and Chevone 1986; Chappelka et al., 1985; Hogsett et al., 1985a). However, growth analysis is not included in this review.

These response measures are examples of "hidden injury" (Heath, 1980), as distinct from visible foliar injury. Foliar injury has been frequently used as an indicator of the relative sensitivity of trees to growth impacts (USEPA, 1986; Davis and Wilhour, 1976), but this practice is suspect. In studies that measured both growth and foliar injury, the two measures have rarely been related. Specifically, growth reduction occurs without visible foliar damage (Reich and Amundson, 1984, 1985; Reich et al., 1986), foliar damage occurs without growth impacts (Jensen and Dochinger, 1974; McClenahan, 1979; Patton, 1981), and rankings of species susceptibility based on growth measures do not correlate with those based on foliar damage (Jensen, 1973; Jensen and Masters, 1975; Wilhour and Neely, 1977; Kress and Skelly, 1982).

Visible foliar damage indicates lost photosynthetic area following a failure of cellular homeostasis. This type of damage occurs most commonly during acute exposure. Lower concentrations of $\mathrm{O}_{3}$ reduce photosynthetic efficiency and increase respiration without this loss of homeostasis. Because short, low concentration exposures cause minimal lasting damage to photosynthesis, hidden injuries are observed as a cumulative result of longer term exposure. While both visible and hidden injuries increase monotonically with 0, levels (McClenahan, 1979; Hogsett et al., 1985b; Chappelka and Chevone, 1986), foliar symptoms appear more sensitive to isolated peak events. The lack of growth reductions despite reduced photosynthetic area suggests compensations in $\mathrm{C}$ allocation and respiration. Differing species susceptibilities suggest that some protection mechanisms are more important for visible damage, while others are more important for hidden injury processes. However, until the mechanistic differences between visible and hidden responses are more clearly understood, foliar injury should not be used as a proxy for more subtle growth effects.

\section{RESULTS OF CONTROLLED FUMIGATIONS}

\section{General Information}

Exposure-response data are summarized in Tables 1 to 3, which cover dry mass (biomass) growth, height growth, and photosynthesis, respectively. As many studies as possible were included, spanning a range of experimental design, methodological rigor, and statistical power. In many cases, response measures were calculated or estimated from graphs. Fumigations employing levels of 0 , greater than $0.40 \mu \mathrm{L} / \mathrm{L}$ were excluded as unrealistic. For those studies that reported repeated measures of response, only those data from the longest fumigation were presented.

The use of different exposure systems and regimes complicates comparison of study results. While most indoor studies used moderate humidities $(50-70 \%)$ and temperatures $\left(20-50^{\circ} \mathrm{C}\right.$ ), other environments (OTC, greenhouse, chamberless) cannot be so readily characterized. Although the tables note some important variables, they are not substitutes for the original references. Variables of importance that must be gleaned from the references themselves include details of exposure regime (variance, sequence of exposures), tissue measured (whole tree, firstyear needle, etc.), season (spring, summer, winter), and genotype selected (sensitive to foliar damage, clones). Unfortunately, no controlled studies are available on seedlings more than $4 \mathrm{yr}$ old.

Data are organized by taxonomic group, noted on the left. Three measures of exposure regime are shown: days actually exposed, average $\mathrm{O}_{3}$ concentration, and dose ( $\mu \mathrm{L} / \mathrm{L}$-hours). Dose is the product of average concentration, days of exposure, and hours fumigated per day (not shown). Dose as used here does not indicate 0 , actually taken up by the plants. Response is shown as percent change from control. Thus, negative numbers indicate growth (photosynthesis) reduction.

Data are included from any study in which response comparisons of at least two concentrations could be made. Regression or confidence interval data would aid interpretation, but these measures were seldom presented. Therefore, asterisks in the tables only indicate whether the response measure for that treatment level was found significantly different from control measures at the 0.05 level. Reich and Lassoie (1985) did not test individual 
Table 1. Effects of controlled $O$, fumigation on weigbt growth in tree seedlings. $\dagger$

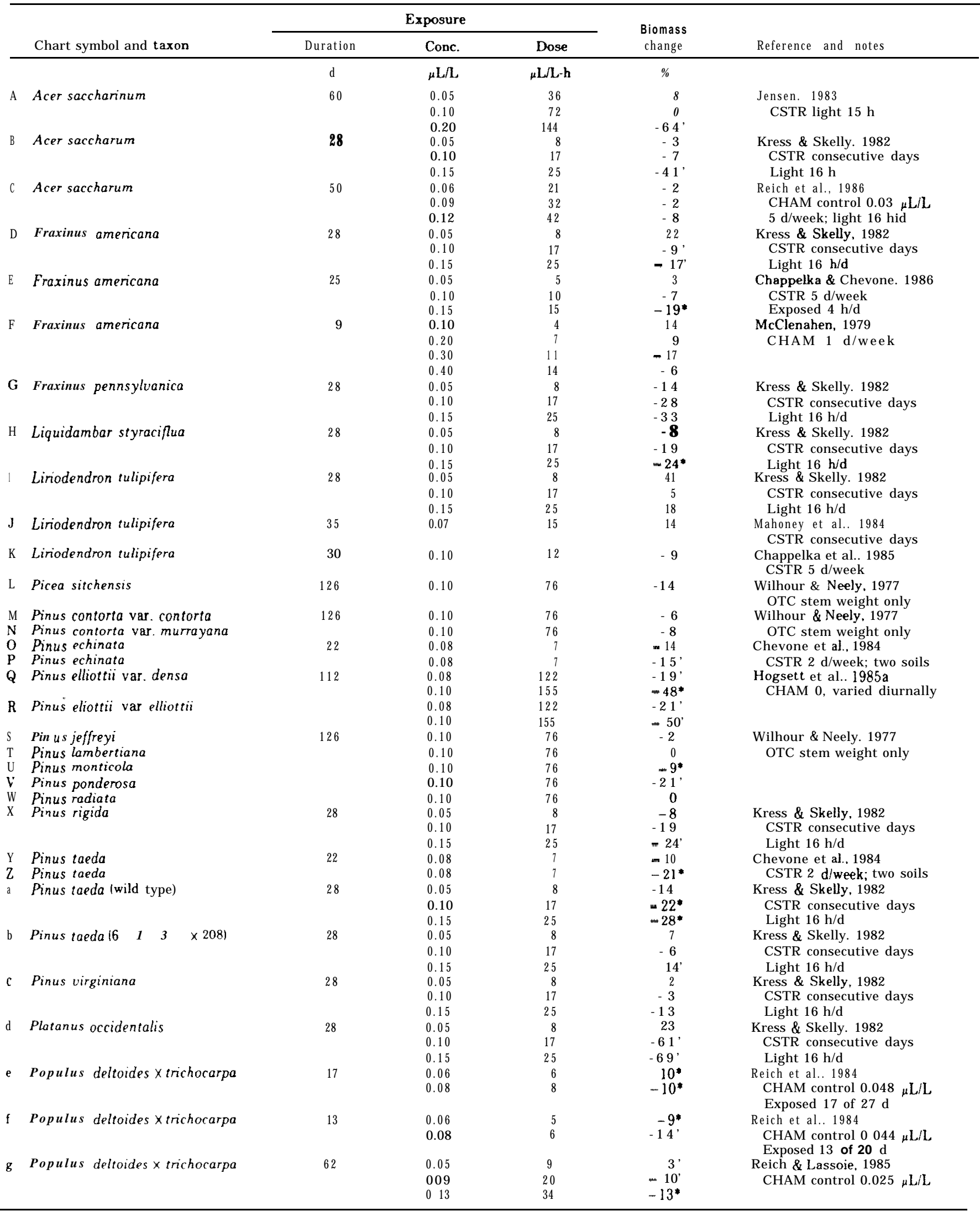

(continued on next page) 
Table 1. Continued.

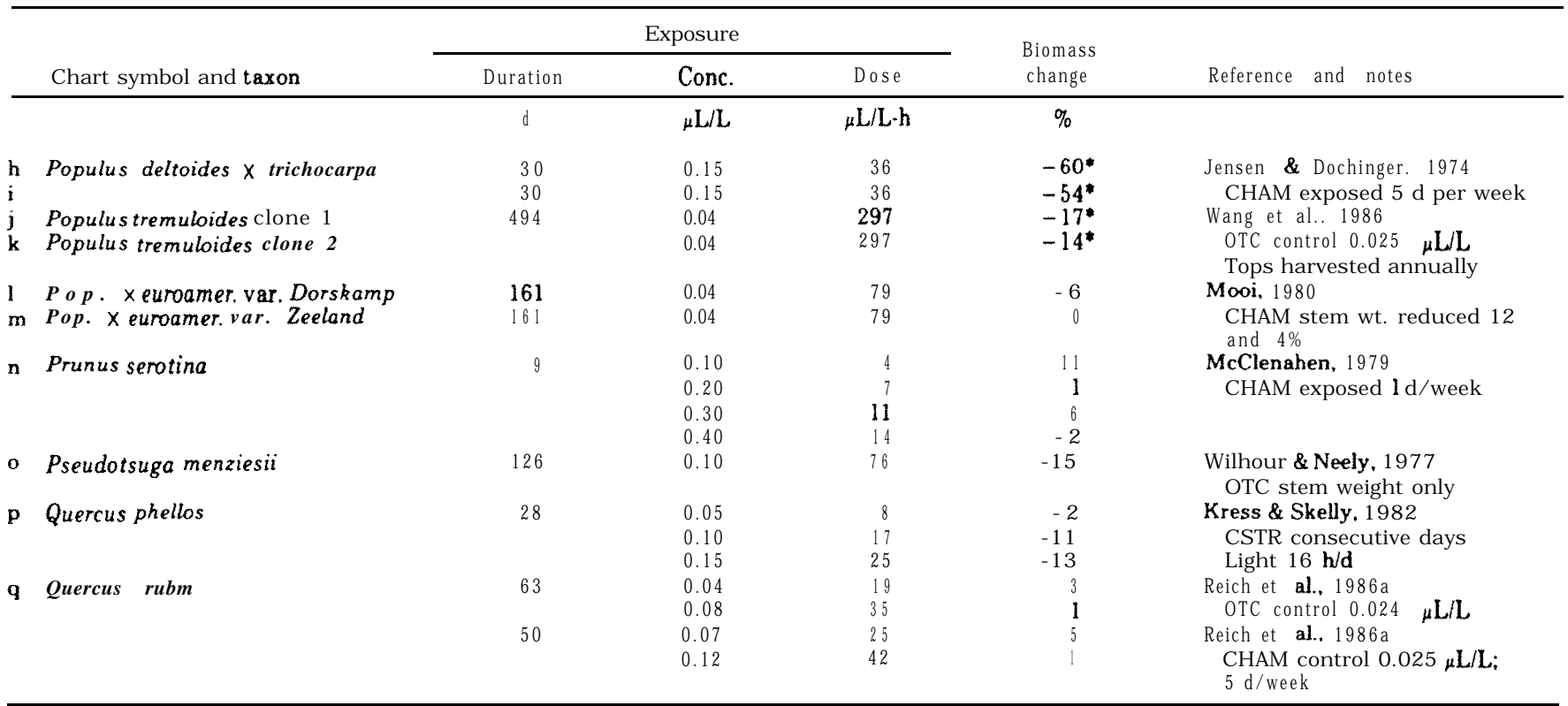

Significant difference from the control at the 0.05 level.

$\dagger$ Dose is the product of average concentration $x$ days of fumigation $x$ hours fumigated per day. Duration refers to actual fumigation days. Response is expressed as percentage change over control. CHAM. CSTR. and OTC refer to chamber, continuously stirred tank reacter, and open-top chamber, respectively.

Table 2. Effects of controlled $\mathrm{O}_{3}$ fumigation on height growth in tree seedlings. $\dagger$

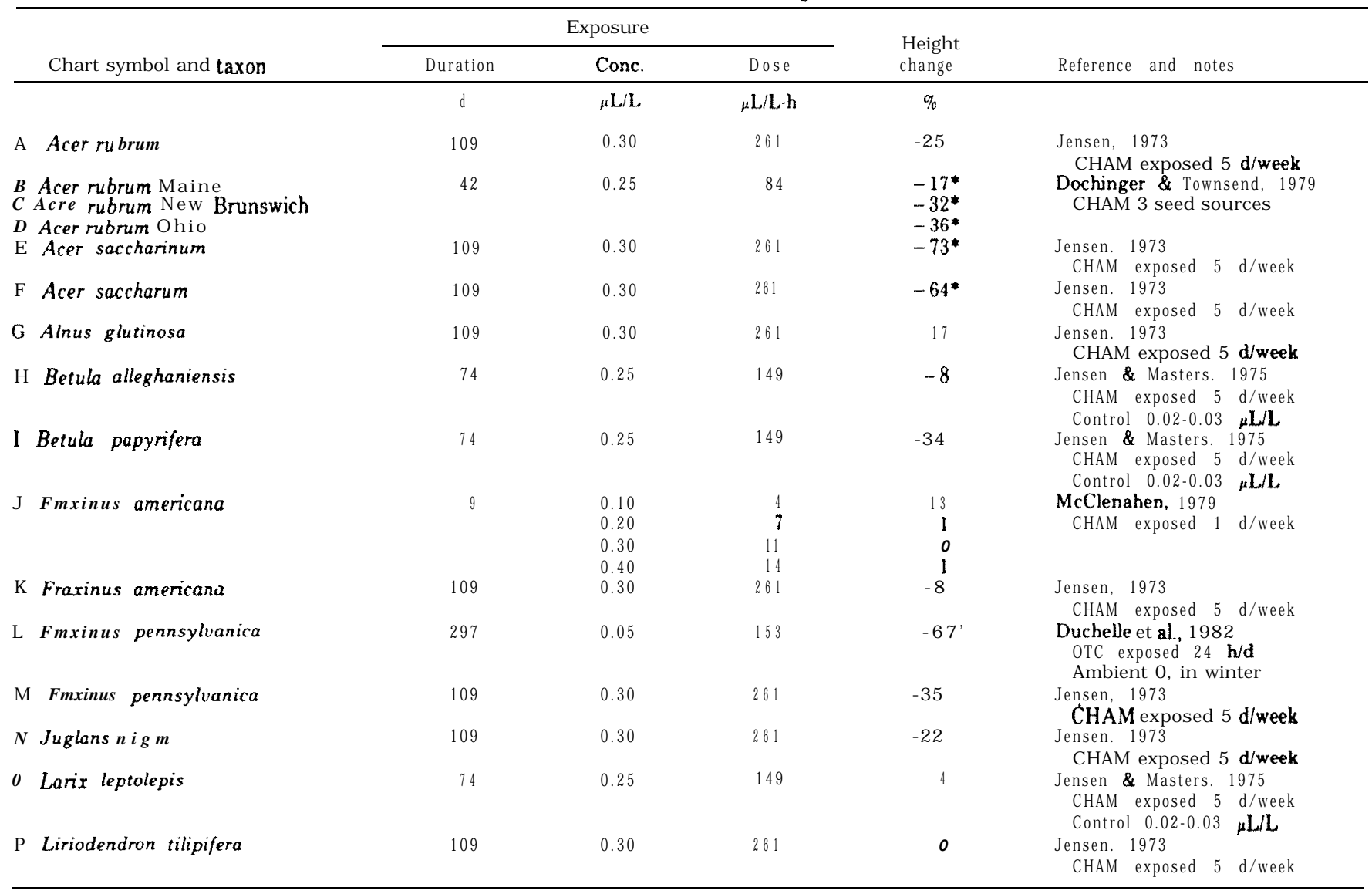


Table 2. Coutiaued.

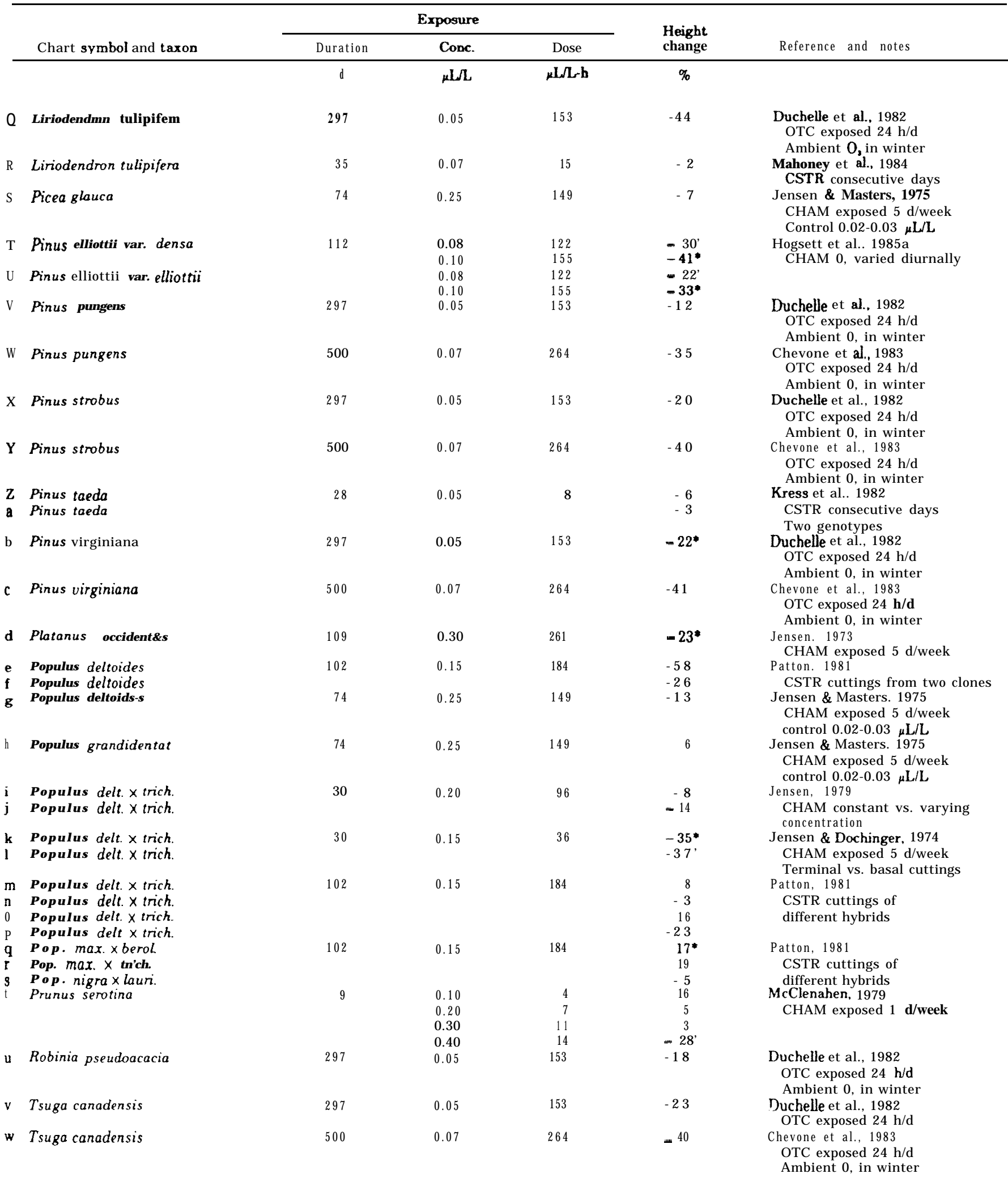

- Significant difference from the control at the 0.05 level.

$t$ Dose is the product of average concentration $x$ days of fumigation $\times$ hours fumigated per day. Duration refers to actual fumigation days. Response expressed as percentage change over control. CHAM. CSTR. and OTC refer to chamber. continuously stirred tank reacter, and open-top chamber. respectively. 
Table 3. Effects of controlled $O_{3}$ fumigation on photosynthesis (Ps) in tree seedlings. $\dagger$

\begin{tabular}{|c|c|c|c|c|c|}
\hline \multirow[b]{2}{*}{ Chart symbol and taxon } & \multicolumn{3}{|c|}{ Exposure } & \multirow{2}{*}{$\begin{array}{c}\text { PS } \\
\text { change }\end{array}$} & \multirow[b]{2}{*}{ Reference and notes } \\
\hline & Duration & Conc. & Dose & & \\
\hline & d & $\mu \mathrm{L} / \mathrm{L}$ & $\mu L / L-h$ & $\%$ & \\
\hline \multirow[t]{3}{*}{ A Acer saccharum } & 50 & 0.06 & 21 & $-13^{*}$ & Reich et $\mathrm{al}, 1986 \mathrm{~s}$ \\
\hline & & 0.09 & 32 & $-19^{*}$ & CHAM control $0.03 \mu \mathrm{L} / \mathrm{L}$ \\
\hline & & 0.12 & 42 & $-28 *$ & Exposed 5 d/week \\
\hline \multirow[t]{3}{*}{ B Pinus elliottii } & 36 & 0.05 & 29 & 19 & Barnes. 1972 \\
\hline & 77 & & 62 & 78 & CHAM exposed 24 h/d \\
\hline & 84 & & 67 & -11 & Light for $16 \mathrm{~h}$ \\
\hline \multirow[t]{2}{*}{$C$ Pinus elliottii } & $\begin{array}{l}36 \\
77\end{array}$ & 0.15 & $\begin{array}{r}86 \\
185\end{array}$ & -23 & 8-month-old seedlings \\
\hline & a 4 & & 202 & -26 & \\
\hline D Pinus elliottii & 126 & 0.05 & 101 & $-9 *$ & Barnes, 1972 \\
\hline \multirow[t]{3}{*}{ E Pinus semtina } & 36 & 0.05 & 29 & 20 & Barnes, 1972 \\
\hline & 77 & & 62 & 100 & CHAM exposer.24 h/d \\
\hline & a 4 & & 67 & 12 & 8-month-old seedlings \\
\hline \multirow[t]{3}{*}{ F Pinus serotina } & 36 & 0.15 & 86 & -6 & \\
\hline & 77 & & la5 & 78 & \\
\hline & a 4 & & 202 & -3 & \\
\hline G Pinus strobus & 35 & 0.05 & 28 & 9 & $\begin{array}{l}\text { Barnes. } 1972 \\
\text { CHAM whole plant (4 months old) }\end{array}$ \\
\hline \multirow[t]{3}{*}{ H Pinus strobus } & 19 & 0.05 & 15 & -2 & Barnes, 1972 \\
\hline & 36 & & 29 & -6 & CHAM secondary needles \\
\hline & 77 & & 62 & -10 & 2-year-old seedlings \\
\hline \multirow[t]{3}{*}{ \Pinus strobus } & 19 & 0.15 & 46 & $-10^{*}$ & \\
\hline & 36 & & 86 & -22 & \\
\hline & 77 & & 185 & -5 & \\
\hline \multirow[t]{2}{*}{$\mathbf{J}$ Pinus taeda } & $\begin{array}{l}36 \\
77\end{array}$ & 0.05 & $\begin{array}{l}29 \\
62\end{array}$ & 8 & $\begin{array}{l}\text { Barnes. } 1972 \\
\text { CHAM exposed } 24 \text { h/d }\end{array}$ \\
\hline & a 4 & & 67 & -7 & 8-month-old seedlings \\
\hline \multirow[t]{3}{*}{ K Pinus taeda } & 36 & 0.15 & 86 & -14 & \\
\hline & 77 & & la5 & -6 & \\
\hline & a4 & & 202 & -5 & \\
\hline L Pinus taeda & 126 & 0.05 & 101 & $-15 *$ & $\begin{array}{l}\text { Barnes. } 1972 \\
\text { CHAM exposed } 24 \text { h/d } \\
\text { I-week-old seedlings }\end{array}$ \\
\hline \multirow[t]{2}{*}{ M Populus delt. $\times$ trich. } & 58 & 0.09 & 27 & $-61 *$ & Reich, 1983 \\
\hline & & 0.13 & 40 & $-87^{*}$ & $\begin{array}{l}\text { CHAM control } 0.025 \mu \mathrm{L} / \mathrm{L} \\
\text { Oldest leaves }\end{array}$ \\
\hline \multirow[t]{2}{*}{ N Quercus rubra } & 50 & 0.07 & 25 & $-10^{*}$ & Reich et al., 1986a \\
\hline & & 0.12 & 42 & $-11 *$ & $\begin{array}{l}\text { CHAM control } 0.02 \mu \mathrm{L} / \mathrm{L} \\
\text { Exposed } 6 \mathrm{~d} / \text { week }\end{array}$ \\
\hline
\end{tabular}

* Significant difference from the control at the 0.05 level.

+ Dose is the product of average concentration $x$ days of fumigation $x$ hours fumigated per day. Duration refers to actual fumigation days. Response expressed as percentage change over control. CHAM. CSTR, and OTC refer to chamber. continuously stirred tank reacter, and open-top chamber. respectively.

treatment differences, although a linear relation between 0 , concentration and biomass of Populus deltoides $\mathbf{x}$ trichocarpa was statistically significant.

Different control $\mathrm{O}_{3}$ levels pose another comparability problem. Controls known to differ substantially from zero are reported in the notes. Unadjusted treatment 0 , levels are reported in the tables, but dose calculations are based on treatment concentration less control. For 24-h fumigations, it is assumed that 0 , concentrations (and stomatal conductance) are negligible at night, and therefore nighttime hours are not included in dose calculations.

\section{Effects on Biomass Growth}

Table 1 reports results of 15 studies on 26 species or hybrids. Exposures employed reflect a trade-off between 0 , concentration and duration, ranging from $0.40 \mu \mathrm{L} / \mathrm{L}$ for $4 \mathrm{~h}$ on each of $9 \mathrm{~d}$ (McClenahen, 1979) to one study spanning three growing seasons that employed 0 , concentrations only $0.018 \mu \mathrm{L} / \mathrm{L}$ over the $0.025 \mu \mathrm{L} / \mathrm{L}$ controls (Wang et al., 1986). This review highlights relative- ly low concentrations, but the treatment durations shown in Table 1 reflect limitations of funding and logistics; only the Wang et al. (1986) study went beyond one growing season. This 3-yr study of fast growing poplar in opentop chambers was made feasible by harvesting aboveground portions of the plants at the end of each of the last two growing seasons. Unfortunately, this removal altered $\mathrm{C}$ allocation and made growth results difficult to interpret.

Studies have measured growth responses in different portions of the plant, including stems (Wilhour and Neely, 1977), all aboveground parts (Jensen 1983; Reich et al., 1984; Wang et al., 1986), and both above- and belowground portions (McClenahan, 1979; Kress and Skelly, 1982; Mahoney et al., 1984; Hogsett et al., 1984a; Reich and Lassoie, 1985; Chappelka and Chevone, 1986). Because aboveground growth is usually less impacted than growth below ground (Hogsett et al., 1985a; Chappelka and Chevone, 1986), studies reporting only aboveground effects probably understate total plant effects. Final weights are reported as growth where growth 
data are unavailable and initial biomass is deemed trivial (Wilhour and Neely, 1977; Chevone et al., 1984).

Responses to 0, range from a growth reduction of $69 \%$ in sycamore (Platanus occidentalis L.) to a growth stimulation of $41 \%$ in yellow poplar (Liriodendron tulipifera L.). However, 28 reductions and no stimulations were found statistically significant. The highconcentration McClenahan study (1979) did not produce significant growth changes, perhaps because fumigation consisted of only nine 4-h fumigations administered over a 9-week period.

The range 0.04 to $0.06 \mu \mathrm{L} / \mathrm{L}$ can be taken as representative of seasonal means prevalent in many forested areas of the USA. Within this range, 13 of 22 studies reported at least nominal growth reductions. However, only five proved statistically different from controls, all of them on species of poplar (Populus) or pine (Pinus). This species bias may be an artifact of better experimental designs or an indication of greater sensitivity in these species. At least in the case of poplar, greater sensitivity seems indicated (Reich, 1987).

The statistical power of study designs is particularly important near ambient concentrations where policy interests are highest. The relatively small growth impacts likely to occur in this range have been difficult to detect with precision. Thus far, problems with statistical design, genetic and environmental variability, and exposure duration have precluded detection of significant growth reductions smaller than $9 \%$.

One attraction of extended fumigations is that they permit measurement of a greater variety of effects, such as changes in bud development and root/shoot ratio. They may also allow identification of small growth differences not detectable in only $1 \mathrm{yr}$ of growth. Longer exposures appear better able to demonstrate growth reductions at low concentrations. Wang et al. (1986) demonstrated a significant reduction in growth under the lowest concentration above the control, but the largest impacts appeared to occur during the first full growing season of the fumigation (second in study).

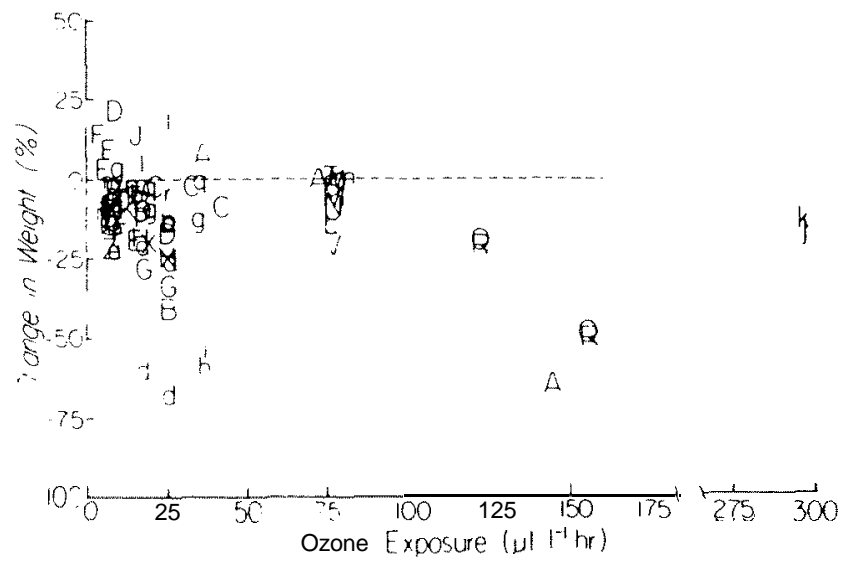

Fig. 1. Effect of 0 , fumigation on biomass (dry mass) growth, expressed as a percentage difference from growth of controls. Abscissa is fumigation 0 , dose less dose used for controls. R efer to Table 1 for explanation of symbols.
Figure 1 plots biomass response in terms of dose. Doses range from 4 to $297 \boldsymbol{\mu L} / \mathbf{L}$-hours. Increased dosages were associated with reduced growth, but there was substantial variation in response. Point symbols indicating individual taxa/study combinations are referenced in the first column of Table 1. Pines, poplars, sycamore (Platanus sp.), ash (Fraxinus sp.) and maple (Acer sp.) are relatively sensitive. The few tests of shade-tolerant species prevent conclusions regarding the importance of this silvical characteristic to sensitivity.

\section{E ffects on $\mathrm{H}$ eight G rowth}

The 12 studies reporting height growth impacts show a similar trade-off between concentration and duration as those reporting biomass effects (Table 2). Longer studies are Chevone et al. (I 983) (three growing seasons) and Duchelle et al. (1982) (two growing seasons). However, low replication and variable soil and planting stock limited their ability to discriminate growth responses. Wang et al. (1986) reported shoot heights, but their results are omitted because of uncertain comparability.

Height responses are somewhat smaller than those for biomass, ranging from $+19 \%$ for the hybrid Populus maximowiczii x P. trichocarpa to $-67 \%$ for Fraxinus pennsy/vanica. However, responses at $0.05 \mu \mathrm{L} / \mathrm{L}$ are as large as those at 0.30 . The large responses at $0.05 \mu \mathrm{L} / \mathbf{L}$ were from the two longest studies. When duration is taken into account through dose (Fig. 2), a negative slope becomes apparent. However, growth responses at high doses are highly variable. Only one growth stimulation was significantly different from control (Populus maximowiczï $\boldsymbol{x} \boldsymbol{P}$. berolinensis).

Sensitivity measured by height response was similar to that based on biomass response. Maples, ash, and some pines appear to be relatively sensitive. The response of poplars, however, was extremely variable. Patton (1981) found height responses of poplar varieties ranged from +19 to $-58 \%$ on exposure to $0.15 \mu \mathrm{L} / \mathrm{L}$.

Ozone may alter seedling height differently from other dimensions, such as diameter. Alteration of form reflects $C$ allocation changes, and in large trees could indicate

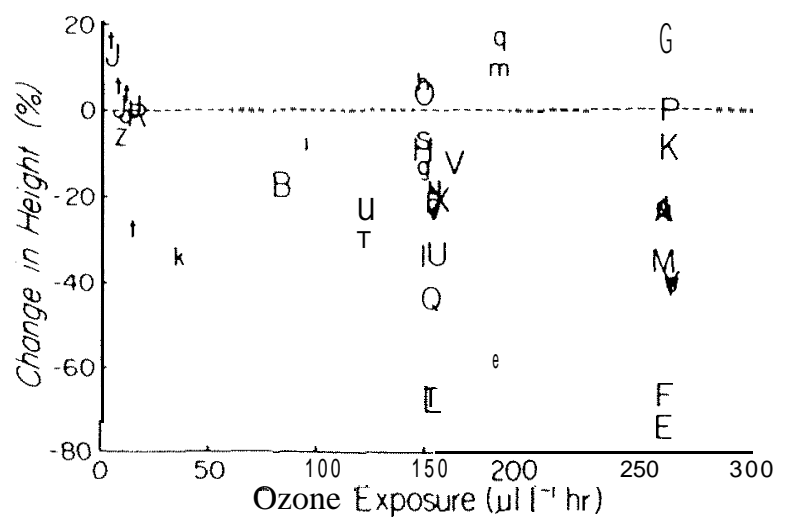

Fig. 2. Effect of 0 , fumigation on height growth. Abscissa is fumigation 0 , dose less dose used for controls. Refer to Table 2 for explanation of symbols. 
altered stress tolerance and merchantability. One explicit test of form change can be made with data from studies that report both proportional height and weight responses (McClenahen, 1979; Hogsett et al., 1985a; Jensen and Dochinger, 1974; Kress and Skelly, 1982). Based on 47 species-concentration combinations, weight responses were 0.88 times height responses, but not significantly different from 1.00 . Thus, while a form change in response to 0 , is not ruled out, more data, preferably from longer fumigations, are needed to be conclusive.

\section{Effects on Photosynthesis}

Table 3 presents data from three studies measuring effects of moderate concentrations of $\mathrm{O}_{3}$ on photosynthesis in tree species. Reported is maximum apparent, or net photosynthesis, measured as net $\mathrm{C}$ assimilation at saturation light intensity. Gross photosynthesis (excluding light respiration) was not measured separately in any of these studies, but because dark respiration is known to be affected by $\mathrm{O}_{3}$ (Barnes, 1972), it is likely that the photosynthetic responses reported here are a sum of reductions in gross photosynthesis and increases in light respiration.

Photosynthetic responses to 0 , can occur almost immediately, or only after prolonged exposure. Under uncommonly high concentrations, response can be detected within less than $30 \mathrm{~min}$ (Hill and Littlefield, 1969). However, at the more realistic concentrations used in the studies in Table 3, responses only developed after a month or more of exposure, apparently reflecting a cumulative and lasting response. Unfortunately, explicit tests of the reversibility of the changes have not been conducted. However, many studies of photosynthesis effects under chronic 0 , exposure measure photosynthesis in the absence of 0 ,. In these cases, leaves are permitted recoveries from 0 , of $15 \mathrm{~min}$ or more before measurement.

Photosynthetic response studies were limited to a single growing season. These fumigations produced apparent responses ranging from +100 to $-87 \%$ (Fig. 3). Once again, hybrid poplars show the largest reductions, up to $87 \%$ at $0.125 \mu \mathrm{L} / \mathrm{L}$. Most other studies reported reductions of less than $25 \%$. The Barnes (1972) study suffered from extreme variability, with very few measures prov-

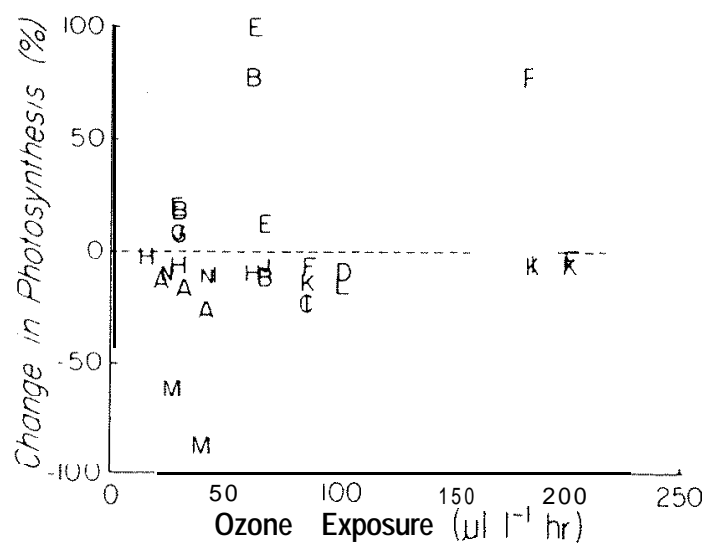

Fig. 3. Effect of $O$, fumigation on photosynthesis. Abscissa is fumigation 0 , dose less dose used for controls. Refer to Table 3 for explanation of symbols. ing significant despite substantial differences among means. None of the apparent stimulations of photosynthesis were significantly different from controls.

A number of factors complicate simple extrapolation from photosynthesis to whole plant growth. For example, respiration, photosynthate allocation, and needle retention are all important factors in plant growth, and each has been shown to be affected by 0 ,. Reich (1987) compared the impacts of $\mathrm{O}_{3}$ on photosynthesis and growth and found that relative effects on growth were only 25 to $50 \%$ as large as those on photosynthesis. It is important to realize, however, that while growth is a measure of total impacts throughout the exposure, photosynthesis in these studies is measured only at the end of the exposure. If $\mathrm{O}_{3}$ damage to photosynthesis is cumulative, as it appears to be, one would expect growth measures to understate effects on photosynthesis observed at exposure end. Growth should be more reflective of the integral of photosynthesis over the course of the exposure, rather than merely at its endpoint. Thus, because 0 , exposure progressively reduces photosynthesis, growth measures must lag those of photosynthesis.

\section{EXTRAPOLATION DIFFICULTIES}

Prolonged exposure to common ambient 0, levels can significantly reduce biomass growth, height growth, and photosynthesis in seedlings of a wide range of taxa. Reductions of $20 \%$ at concentrations below $0.10 \mu \mathrm{L} / \mathrm{L}$ are common. Stimulation of growth at low concentrations, as has been proposed for pollutants in general (Smith, 1981), cannot be ruled out from these studies because no treatments have been conducted at less than $0.04 \mu \mathrm{L} / \mathrm{L}$, and because of limited ability to detect small changes in growth. However, the nearly total absence of significant stimulations at levels of 0 , greater than 0.04 $\mu \mathbf{L} / \mathbf{L}$ suggests that stimulation is minor or transitory. This is in contrast to pollutants such as NO, and SO, that are known to have nutritional benefits.

Reich (1987) concluded from his review of tree response data that conifers are at least initially less sensitive to $\mathrm{O}_{3}$ than hardwoods. These data do not show such a pattern. His conclusion may result from the large number of observations employing poplar. Because poplar is unusually sensitive, its extreme response may have overstated the general sensitivity of hardwoods.

\section{Seedling Level Issues}

Both concentration and duration are important factors governing impact on growth and photosynthesis, but they probably are not equally important. In his broader review of 0, impacts on photosynthesis, Reich (1987) showed nonlinear response in pine and crop species, with higher concentrations having a disproportionately large impact on growth. However, he was able to use a linear approximation of response when restricting concentrations to more realistic levels. None of the seedling fumigation studies thus far have been able to demonstrate a higher order response than linear. However, the biomass data here do suggest such a nonlinear response, with nominally 
convex exposure series outnumbering concave series three to one.

The presence of convexity implies that for similar mean 0 , exposures, damage will be greater when 0 , concentrations are more variable. This appears the case for crops (Hogsett et al., 1985b) and data suggests it may also be true for trees (Jensen, 1979). However, very little tree research has been done on this question, and even less on the related issue of respite.

Duration of exposure poses a number of problems not evident from the data shown thus far. Jensen (1973) measured height growth of nine hardwood species throughout a 5-month fumigation. He found a bewildering array of patterns of response over time-, including initial stimulation followed by reduction (red maple), initial reduction followed by later recovery to normal height (yellow poplar), immediate and continuing reductions (green ash, silver maple), and delayed reduction (sycamore). These differences were not related to differences in growth habit. In this study, cessation of the experiment after 1 or 2 months would have produced quite different conclusions than after the full 5 months. Only longer fumigations can determine whether similar changes in response occur over longer periods.

Another complication in extrapolating from short to long fumigations involves leaf phenology. In the absence of 0 , leaf photosynthetic capacity reaches an early peak and then declines gradually until senescence. Reich (1983) found that exposure accelerates this change. The result is an increasing divergence from photosynthesis in control leaves of the same age, ending in early senescence. If this pattern holds for other species, fixed-growth species, which produce all of their leaves early in the season (Kramer and Kozlowski, 1979), will suffer increasing reductions in photosynthesis as leaves age in synchrony. Free growth species produce new and therefore undamaged leaves repeatedly through the season. Because growth of later leaves depends on $\mathrm{C}$ gained from early leaves, however, late-season effects of 0 , may include iower leaf areas or increased leaf turnover through early senescence (Jensen, 1982). Mooi (1980) found that in indeterminate poplar, late-season leaf area was reduced nearly two-thirds by 0 , , but total leaf production in that growing season was virtually unchanged.

Conifers that retain needles more than $1 \mathrm{yr}$ further complicate extrapolation to long-term effects. The progressive damage found in shorter-lived poplar leaves has not been assessed in conifers for even several months of fumigation, much less for the normal life of a needle. In polluted areas, longer lived foliage would be subjected to more opportunities for exposure. However, retention of foliage in winter may permit some recovery in conifer foliage in the lower 0 , concentrations of winter. Only long-term fumigations with repeated measures of photosynthesis on the same cohort of needles for $1 \mathrm{yr}$ or more can resolve these issues.

Early leaf senescence and increased turnover represent $\mathrm{C}$ drains on the plant that may reduce or delay leaf deployment and alter root/shoot allocation in succeeding years. Reduced leaf area, photosynthetic efficiency, root/shoot ratio, and stemwood production are all manifestations of altered $\mathrm{C}$ allocation patterns. Such $\mathrm{C}$ allocation differences have been directly measured in trees of differing susceptibilities to $\mathrm{O}_{3}$. McLaughlin et al. (1982) used ${ }^{14} \mathrm{C}$ labeling to demonstrate that branches from symptomatic trees exported less $\mathrm{C}$ to stem and roots than branches from asymptomatic trees, and attributed this to higher dark respiration rates and lowered needle length and retention in symptomatic trees. However, it is unclear how comparisons between different individuals under the same 0 , exposure relates to differences that would occur to the same trees under different exposures to 0 ,.

Identification of these long-term impacts of $\mathrm{O}_{3}$ on $\mathrm{C}$ allocation will require realistic exposure conditions, including those belowground. Peat-vermiculite "soils," fertilization, and irrigation minimize controls on top growth common under forest conditions. Thus, unrealistically favorable soil regimes probably understate reductions in top growth that would occur under less favorable field conditions. Adequate assessment of $\mathrm{C}$ allocation impacts will await fumigations of several years under realistic above- and belowground conditions.

Alteration of root/shoot ratio is one way that 0 , can impact drought susceptibility. A second mechanism is stomata1 control. Reich and Lassoie (1984) found that 0 , lowered water use efficiency of poplar leaves by impairing stomatal control. Stomatal conductance of exposed leaves was less responsive, with higher conductance in the dark, and exposed leaves were less able to resist wilting by closing stomates. These experimental results agree with uncontrolled observations on symptomatic ponderosa pine in the high-O, San Bernardino region (Coyne and Bingham, 1982). Understanding drought interactions will require assessment of the importance of both these mechanisms.

\section{Extrapolation to Mature Trees}

Several factors complicate extrapolation of seedling data to larger trees, including the ratio of metabolic to catabolic tissue, the existence of microclimatic and morphologic gradients across a canopy, and altered water and nutrient regimes.

As a tree ages, the fraction of tissue that is photosynthetically inactive grows (Kramer and Kozlowski, 1979). Cambial tissues associated with stem, branch, and coarse roots also increase. Extrapolations from seedlings to large trees must account for the differing balance between photosynthesis and respiration that these changes entail.

While the basic metabolic processes of foliage are similar in young and old trees, the environment in which the leaf develops affects its morphology. The microclimatic gradient generated by deep forest canopies is paralleled by a morphologic gradient from sun leaves to shade leaves. The most obvious environmental factor in this gradient is net radiation, which can vary by an order of magnitude within the canopy (Lee, 1978). From above to below crown, wind speed decreases, air temperature decreases and becomes less variable, and humidity and CO, increase (Lee, 1978). Ozone concentration could also 
vary with forest crown depth, but tests of this have not yet been reported.

These microclimatic factors have short- and long-term impacts. Immediate effects are exerted through stomata1 control and metabolic processes. All of the gradient variables cited above affect stomatal opening (Salisbury and Ross, 1978) and thus potentially $\mathrm{O}_{3}$ uptake. Hill and Littlefield (1969) found that reductions of photosynthesis from 0 , were larger at high than at low intensities of artificial light, when reduction was expressed as a fraction of respective control levels. High humidity also increases susceptibility to $\mathrm{O}_{3}$, acting through both stomatal and nonstomatal factors (McLaughlin and Taylor, 1981). Temperature alters susceptibility to acute $O_{3}$ 'damage (Davis and Wood, 1973), but in a complex manner. While high temperatures during exposure protected plants from foliar damage, plants preconditioned or postconditioned to higher temperatures were more sensitive. The role of stomates was not investigated, but was probably important.

Leaf morphology represents a longer-term response of leaves to microclimatic canopy gradients. In their comparison of the effects of indoor vs. outdoor environments on acute 0, susceptibility, Lewis and Brennan (1977) noted that leaves from outdoor-grown plants were morphologically more similar IO sun leaves, with thicker leaves and higher stomatal frequency than those grown indoors. Lewis and Brennan (1977) found that leaves from open-top chambers were less sensitive to foliar injury than those from indoor environments, but it is unclear how foliar sensitivity relates to growth or photosynthetic responses.

Water transport differs between young and old trees, and the difference may alter susceptibility to 0 ,. Uptake of 0 , and presumably impact on photosynthesis, depends on how daily and seasonal patterns of stomatal conductance correspond to patterns of 0 , exposure. Because large trees store water in their stems, permitting a greater lag between leaf transpiration and root absorption (Kramer and Kozlowski, 1979), tree stem size can influence temporal patterns of stomatal conductance, and hence uptake and impact of 0 ,.

Availability of different nutrients can change during stand development in response to uptake and storage in vegetation and soil (Bormann and Likens, 1979). However, the interactions of 0 , and nutrition are complex and poorly understood (Cowling and Koziol, 1984; Skeffington and Roberts, 1985).

Methods for extrapolating impacts to full-sized trees include fumigation of mature trees (Reich, 1987) and modeling of growth processes. Although fumigation promises realism, high cost will limit replication. The slower relative growth rates of larger trees will make detection of certain responses, such as branch retention and crown shape, difficult to detect.

Modeling provides a method for extrapolation of single tree impacts to a wider range of conditions and time periods. Modeling tree and stand responses to stress is a demanding task that will have to build on research yet to be conducted, including mature tree fumigations, but early efforts based on current information can provide better direction to future research. One strategy would be to focus initial modeling efforts on 0 , effects on leaf processes of photosynthesis, respiration, and senescence. Incorporation of $\mathrm{C}$ allocation changes will require improved mechanistic understanding, as well as data from multiyear fumigations employing realistic belowground conditions. incorporation of nutritional, disease, and fire interactions will likely prove even more difficult.

Photosynthesis and respiration are highly mechanistic response measures, and thus are attractive as model inputs. However, their sensitivity to environmental variables such as light and humidity will require considerable data and complex modeling. Growth analysis integrates these shorter-term responses, but these measures may not be as readily extrapolated to other conditions and are less commonly measured. Stomatal conductance helped explain differences in response between different species and fumigations (Reich, 1987). and it may be helpful in extrapolation from small scale measures to larger scale patterns (Jarvis and McNaughton, 1986). The models that are developed, however, must be able to account for the morphologic changes that occur during stand development, and feedbacks between those changes and the driving physiologic processes.

\section{Extrapolation to Stand Level Yield}

Estimates of effects on stands will rely in part on treelevel effects, but must also account for competitive relations in a stand, and the possible impact of 0 , on those processes. Competition affects species distribution in multispecies stands as well as tree-size distribution in single and multispecies stands. This distribution of sizes is important in the determination of timber value, because larger stems are worth disproportionately more than small stems. Preferential reduction of growth of dominant trees generates a larger economic impact than reductions in growth of suppressed individuals, many of which would die through natural thinning processes.

Simple reduction of the growth rates of all individuals in a stand reduces the overall yield of the stand, and could be modeled as slower stand development or lower site quality. If impacts are not uniform across different sizes of individuals in a stand, however, stand volume and diameter distribution could be altered disproportionately. Simulations by Webb and Burkhart (1987) found that assigning damage to the taller individuals in a stand resulted in much larger reductions to total stand volume than when impacts were randomly assigned.

Differential susceptibility of dominant vs. suppressed individuals can arise from phenotypic or genotypic causes. Phenotypic causes include differential susceptibility of shade vs. sun leaves and 0 , gradients within the canopy. Genotypic causes occur if growth potential is related $10^{\circ} \mathrm{O}_{3}$ susceptibility. Genotypes differ in their susceptibility to 0,, and data from Patton (1981) showed that clones that grew the fastest at low levels of 0 , exhibited the greatest reductions in growth under elevated levels (Fig. 4). Whether such differences are related to genetic differences in stomatal conductance as Reich 


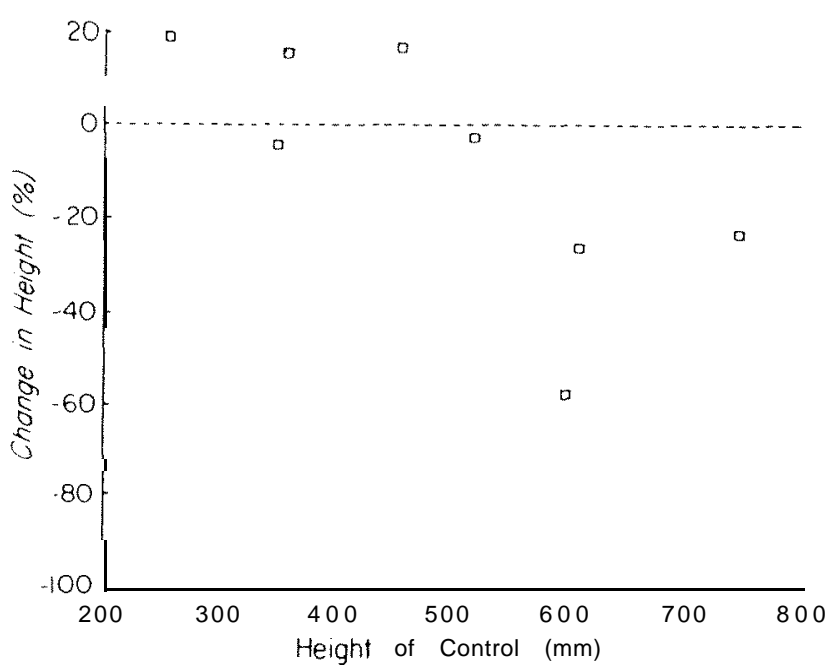

Fig. 4. Effects of 0 , fumigation on height growth of nine poplar clones compared with the height growth of its control. Effects expressed as percentage difference from control growth. Data from Patton. 1981.

(1987) has suggested, or to other genetic differences, such correlations imply that $\mathrm{O}_{3}$ may impact not only total stand volume, but also the distribution of stem sizes in the stand.

Different model features are required to account for phenotypic and genotypic differences. Phenotypic differences require tracking vertical distributions of leaf area and microclimate. Genetic differences require information on the variability of susceptibility between and within different genotypes, as well as the genetic relatedness of individuals in different types of stands. The spatial distribution of different genotypes horizontally must be considered because this influences the ability of the stand to compensate for growth reductions in individual genotypes. Well-mixed stands would be better able to compensate than stands where genotypes are clumped.

Correlations between potential growth rate at low $\mathrm{O}_{3}$ concentrations and 0 , susceptibility may also exist between sites. If conditions that foster fast growth also affect $\mathrm{O}_{3}$ susceptibility, 0 , might have a differential impact on sites of differing site quality. Such differences would be particularly important for economic damage assessment because of the importance of site quality in determining wood production, forest management, and economic return.

Harkov and Brennan (1979) hypothesized that slower growing species, typical in late-successional communities, are less susceptible to oxidant damage than the rapidly growing species typical of early successional stands. Their analysis of this hypothesis used sensitivity rankings based on foliar injury, and results were equivocal. Should their hypothesis apply for growth, however, fast growing species that are most valuable to timber production may be the most susceptible to damage. The data in this review do not permit a definitive conclusion on this issue, but do provide grounds for concern.

Ozone is the most tractable regional pollutant for impact assessment. Substantial research has been conducted to date, immediate mechanisms of effect are reasonably well characterized and directly related to growth processes, and system response to pollutant regulation should be rapid. Even so, research in several critical areas will be necessary before credible extrapolation from controlled experiments can be made. Of critical importance at this time is choice of proper response measurements needed for such extrapolations. While weight and height gain are easily measured impacts, extrapolation to mature trees may necessitate more mechanistic measures, such as photosynthesis and respiration. Models incorporating stomata1 conductance provide one possible means of extrapolating limited photosynthesis measurements to a wider range of climatological and perhaps even genetic conditions. Another approach is growth analysis, which requires periodic harvesting of seedlings, but allows identification of types of impact through easily made morphological measures, and provides a more integrated measure of impact than direct leaf measures of $\mathrm{C}$ fiiation.

While total volume loss estimations will likely form the backbone of a regional timber market impact assessment, differential sensitivity within a canopy may alter processes of stand development, either accelerating or interfering with stand thinning processes. These changes are likely to alter product mix and hence value per unit volume. Such changes are not predictable solely from estimates of volume loss.

Seedling experiments have provided convincing evidence of short-term effects of 0 , on growth. Efforts to estimate impacts on larger scales face a new set of problems requiring close cooperation between physiologists, ecologists, and modelers. This article has suggested several mechanisms by which 0 , might modify competitive interactions between individual trees in a forest. Of critical concern is whether stand processes will compensate for or amplify impacts on individual trees.

\section{ACKNOWLEDGMENTS}

This paper would not have been possible without the support of Drs. J.E. de Steiguer and Greg Ruark. Comments by Drs. William Leuschner, Ram Oren, Shepard Zedaker, Lance Kress, and Keith Jensen are gratefully acknowledged, as are those of Peter Reich.

\section{REFERENCES}

Altshuller, A.P. 1983. Atmospheric concentrations and distributions of chemical substances. p. 5- I to 5-103. In A. P. Altshuller and R.A. Linthurst (ed.) The acidic deposition phenomenon and its effects: Critical assessment review naners U.S. EPA/NCSU Acid Precipitation Program. USEPA, Washington, DC.

Barnes, R.L. 1972. Effects of chronic exposure to 0, on photosynthesis and respiration of pines. Environ. Pollut. 3:133-138.

Bell. J.N.B. 1986. Effects of acid deposition on crops and forests. Experientia 42:363-371.

Berry, C.R. 1964. Differences in concentrations of surface oxidant between vallev and mountaintoo, conditions in the southern Appalachians. J. Air Pollut Control Assoc. 14:238-239.

Bonnickson, T.M.. and R.H. Becker. 1983. Environmental impact studies: An interdisciplinary approach for assigning priorities. Environ. Manage. 7: $10 \% 117$.

Bormann, F.H., and G.E. Likens. 1979. Pattern and process in a forested ecosystem. Springer-Verlag, New York.

Chappelka, A.H., III, and B.I. Chevone. 1986. White ash seedling growth response to ozone and simulated acid rain. Can. J. For. Res. 16:786-790. 
Chappelka, A.H., III, Chevone B.I., and Burk T.E. 1985. Growth response of yellow-poplar (Liriodendron tulipifera L.) seedlings to ozone, sulfur dioxide, and simulated acidic precipitation, alone and in combination. Environ. Exp. Bot. 25:233-244.

Chevone, B.I., J.M. Skelly, and Y.S. Yang. 1983. The influence of ambient pollutants on the growth of seedling forest trees and native vegetation. Aquilo Ser Bot. 19:198-207.

Chevone, B.I., Y.S. Yang, and G.S. Reddick. 1984. Acidic precipitation and ozone effects on growth of loblolly and shortleaf pine seedlings. Phytopathology $74: 756$.

Cowling, D.W., and M.J. Koziol. 1984. Mineral nutrition and plant response to air pollutants. p. 349-375. In M.J. Koziol and F.R. Whatley. (ed.), Gaseous air pollutants and plant metabolism. Butterworth, Boston.

Coyne, P.I., and G.E. Bingham. 1982. Variation in photosynthesis and stomatal conductance in an ozone-stressed ponderosa pine stand: Light response. For. Sci. 28(2):257-273.

Davis, D.D., and R.G. Wilhour. 1976. Susceptibility of woody plants to sulfur dioxide and ohotochemical oxidants: A literature review. EPA-600/3-76-102. USEPA, Washington, DC.

Davis. D.D.. and F.A. Wood. 1973. The influence of environmental factors on the sensitivity of Virginia pine to ozone. Phytopathology 63:371-376.

Dochinger, L.S., and A.M. Townsend. 1979. Effects of roadside deicer salts and ozone on red maple progenies. Environ. Pollut 19:229-237

Duchelle, S.F., J.M. Skelly, and B.I. Chevone. 1982. Oxidant effects on forest tree seedling growth in the Appalachian Mountains. Water Air Soil Pollut. 18:363-373.

Fisher, A.C. 1981. Resource and environmental economics. Cambridge Univ. Press, New York.

Cuderian, R. 1985. Air pollution by photochemical oxidants. Springer-Verlag, New York

Guderian, R., D.T. Tingey, and R. Rabe. 1985. Effects of photochemical oxidants on plants. D. 129-346. In R. Guderian (ed.) Air pollution by photochemical oxidants. Springer-Verlag, New York.

Harkov, R., and E. Brennan. 1979. An ecophysiological analysis of the response of trees to oxidant pollution. J. Air Pollut. Control Assoc. 29: 157-161.

Heagle, A.S. 1984. Interactions between air pollutants and parasitic plant diseases. p. 333-348. In M.J. Koziol and F.R. Whatley (ed.) Gaseous air pollutants and plant metabolism. Butterworth, Boston.

Heath, R.L. 1980. Initial events in injury Io plants by air pollutants. Ann. Rev. Plant Physiol. 31:395-430.

Heck, W.W., A.S. Heagle, and D.S. Shriner. 1986. Effects on vegetation: Native, crops, forests. p. 247-350. In A.S. Stern (ed.) Air pollution. Vol. 6. Academic Press, Inc., New York.

Hill, A.C., and N. Littlefield. 1969. Ozone. Effect on apparent photosynthesis, rate of transpiration, and stomatal closure in plants. Environ. Sci. Technol. 3:52-56

Hogsett, W.E., M. Plocher, V. Wildman, D.T. Tingey, and J.P. Bennett. 1985a. Growth resnonse of I wo varieties of slash oine seedlings to chronic ozone exposures. Can. J. Bot 63:2369-2376

Honsett. W.E. D.T. Tinaev, and S.R. Holman. 1985b. A nrogram mable exposure control system for determination of the effects of pollutant exposure regimes on plant growth. Atmos. Environ. 19:1135-1145.

Holling, C.S., and A.D. Chambers. 1973. Resource science: The nurture of an infant. Bioscience 23:13-20.

Jarvis, P.G., and K.G. McNaughton. 1986. Stomatal control of Iransoiration: Scaline נun, from leaf to region. In A. Macfadven and E.D. Ford (ed.) Adv. Ecol. Res. 15:1-49.

Jeffords. M.R., and A.G. Endress. 1984. Possible role of ozone in tree defoliation by the gypsy moth (Lepidiptera: Lymantriidae). Environ. Entomol. 13:1249-1252

Jensen, K.F. 1973. Response of nine forest tree species to chronic ozone fumigation. Plant Dis. Rep. 57:914-917.

Jensen, K.F. 1979. A comparison of height growth and leaf parameters of hybrid poplar cuttings growth in ozone-fumigated atmospheres. USDA For. Serv. Res. Paper NE-446. Northeastern Forest Exp. Stn., Broomall, PA.

Jensen, K.F. 1981a. Air pollutants affect the relative growth rate of hardwood seedlings. USDA For. Serv. Res. Paper NE-470. Northeastern Forest Exp. Sin., Broomall, PA.

Jensen, K.F. 1981b. Growth analysis of hybrid poplar cuttings fumigated with ozone and sulphur dioxide. Environ. Pollut. Ser.
A $26: 243-250$

Jensen, K.F. 1982. An analysis of the growth of silver maple and eastern cottonwood seedlings exposed to ozone. Can. J. For. Res. $12: 420-424$.

Jensen, K.F. 1983. Growth relationships in silver maple seedlings fumigated with 0 , and SO,. Can J. For. Res. 13:298-302.

Jensen, K.F., and L.S. Dochinger. 1974. Responses of hybrid poplar cuttings to chronic and acute levels of ozone. Environ. Pollut. 6:289-295

Jensen, K.F., and R.G. Masters. 1975. Growth of six woody species fumigated with ozone. Plant Dis. Rep. 59:760-762.

Kercher, J.R., and M.C. Axelrod. 1981. SILVA: a model for forecasting the effects of $\mathrm{SO}_{2}$ pollution on growth and succession in a western coniferous fdrest. Lawrence Livermore Lab., Livermore. CA.

Kozlowski, T.T., and H.A. Constantinidou. 1986a. Responses of woody plants to environmental pollution: Part 1. Sources and types of pollutants and plant responses. For. Abstr. 47:5-51. Kozlowski, T.T., and H.A. Constantinidou. 1986b. Responses of woody plants to environmental pollution: Part 2. Factors affecting responses to pollution and alleviation of pollution effects. For. Abstr. 47:105-132.

Kramer, P.J., and T.T. Kozlowski. 1979. Physiology of woody plants. Academic Press, New York.

Kress, L.W., and J.M. Skelly. 1982. Resnonse of several eastern forest tree species to chronic doses of ozone and nitrogen dioxide. Plant Dis. 66:1149-1 152

Kress, L.W., J.M. Skelly, and K.H. Hinkelmann. 1982. Growth impact of ozone, NO, and/or SO, on Pinus taeda. Environm. Monit. Assess. 1:229-239.

Lee, R. 1978. Forest microclimatology. Columbia Univ. Press, New York.

Lefohn, A.S., and C.K. Jones. 1986. The characterization of ozone and sulfur dioxide air quality data for assessing possible vegetation effects. J. Air Pollut. Control Assoc. 36:1 123-129.

Lewis, E., and E. Brennan. 1977. A disparity in the ozone response of bean plants grown in a greenhouse, growth chamber or opentop chamber. J. Air Pollut. Control Assoc. 27:889-891.

Mahoney, M.J., J.M. Skelly, B.I. Chevone, and I.D. Moore. 1984. Response of yellow poplar (Liriodendron rulipifera L.) seedling shoot growth to low concentrations of $\mathrm{O}_{3}, \mathrm{SO}_{3}$, and $\mathrm{NO}$.. Can. J. For. Res. 14:150-153

Male, L.M. 1982. An experimental method for predicting plant yield response to pollution time series. Almos. Environ. 16:2247-2252.

McClenahen, J.R. 1979. Effects of ethylene diurea and ozone on the growth of tree seedlings. Plant Dis. Rep. 63:320-323.

McLaughlin, S.B., and R.K. McConathy. 1983. Effects of SO, and $\mathrm{O}$, on allocation of "C-labeled phorosythate in Phaseolus vulgaris. Plant physiol. 73:630-635.

McLaughlin, S.B., R.K. McConathy, D. Duvick, and L.K. Mann. 1982. Effects of chronic air pollution stress on photosynthesis, carbon allocation, and growth of white pine frees. For. Sci. $28: 60-70$.

McLaughlin, S.B., and G.E. Taylor. 1981. Relative humidity: Important modifier of pollutant uptake by plants. Science (Washington, D.C.) 21 I : $167-169$.

Miller, P.R. 1983. Ozone effects in the San Bernardino National Forest. p. 161-197. In Davis et al. (ed.) Air pollution and the productivity of the forest. Izaak Walton League, Arlington, VA

Miller, P.R., J.R. Parmeter, Jr., B.H. Flick, and C.W. Martinez. 1969. Ozone dosage response of ponderosa pine seedlings. J. Air Pollut. Control Assoc. 19:435-538.

Miller, P.R., O.C. Taylor, and R.G. Wilhour. 1982. Oxidant air pollution effects on a western coniferous ecosystem. Environ. Res. Brief EPA-600/D-82-276. USEPA, Washington, DC.

Mooi, J. 1980. Influence of ozone on growih of two poplar cultivars. Plant Dis. 64:772-773.

Mudd, J.B. 1984. Effects of oxidants on metabolic function. p. 189-203. In M.J. Koziol and F.R. Whatley (ed.) Gaseous air pollutants and plant metabolism. Butterworth, Boston.

Musselman, R.C., R.J. Oshima, and R.E. Gallavan. 1983. Significance of pollutant concentration distribution in the response of 'red kidney' beans to ozone. J. Am. Hortic. Sci. 108:347-351

National Research Council. 1986. Acid deposition: Long-term (rends. National Academy Press, Washington, DC.

Noble, R.D., and K.F. Jensen. 1980. Effects of sulfur dioxide and ozone on growth of hybrid poplar leaves. Am. J. Bot. 
$67: 1005-1009$

Olszyk, D.M., A. Bytnerowicz, G. Kats, P.J. Dawson, J. Wolf, and C.R. Thompson. 1986. Crop effects from air pollutants in air exclusion systems vs. field chambers. J. Environ. Qual. $15: 417-422$.

Panshin, A.J.. C. deZeeuw, and H.P. Brown. 1964. Textbook of wood technology. Vol. 1. McGraw-Hill Book Co., New York.

Patton, R.L. 1981. Effects of ozone and sulfur dioxide on height and stem specific gravity of Populus hybrids. USDA For. Serv Res. Paper NE-471. Northeastern For. Exp. Stn., Broomall, PA.

Pinkerton, J.E., and A.S. Lefohn. 1986. Characterization of ambient ozone concentrations in commercial timberlands using available monitoring data. TAPPI J.

Rehfuess, K.E., C. Bosch, and E. Pfannkuck. 1982. Nutrient imbalance in coniferous stands in southern Germany. In International Workshop on Growth Disturbances of Forest Trees. Int. Union For. Resh Organ., Jyvaskyla, Finland.

Reich. P.B. 1983. 'Effects of low concentrations of O, on net photosynthesis, dark respiration, and chlorophyll contents in aging hybrid poplar leaves. Plant Physiol. 73:291-296.

Reich, P.B. 1987. Quantifying the response of plants to ozone: A unified explanation. Tree Physiol. 3:63-91.

Reich, P.B., and J.P. Lassoie. -1984. Effects of low level 0, exposure on leaf diffusive conductance and water-use efficiency in hybrid poplar. Plant Cell Environ. 7:661-668.

Reich, P.B., and R.C. Amundson. 1984. Low level O, and/or SO, exposure causes a linear decline in soybean yield. Environ. Pollut. 34:345-355

Reich, P.B., and R.G. Amundson. 1985. Ambient levels of ozone reduce net ohotosynthesis in tree and crop species. Science (Washington, D C ) 230:566-570.

Reich. P.B.. and J.P. Lassoie. 1985. Influence of low concentrations of ozone on growth, biomass partitioning, and leaf senescence in young hybrid poplar plants. Environ. Pollut. 39:39-51.

Reich, P.B., J.P. Lassoie, and R.G. Amundson. 1984. Reduction in growth of hybrid poplar following field exposure to low levels of 0, and (or) SO,. Can. J. Bot. 62:2835-2841.

Reich, P.B., A.W. Schoettle, and R.G. Amundson. 1986. Effects of 0 , and acidic rain on uhotosvnthesis and growth in sugar maple and northern red oak seedlings. Environ. Pollut 40:1-15.

Roberts, T.M. 1984. Effects of air pollution on agriculture and forestry. Atmos. Environ. 18:629-652.

Runeckles, V.C. 1986. Photochemical oxidants. p. 265-303. In A.H. Legge and S.V. Krupa (ed.) Air pollutants and their effects on the terrestrial ecosystem. John Wiley \& Sons, Inc.. New York.
Salisbury, F.B., and C.W. Ross. 1978. Plant physiology. Wadsworth Publishing Co., Inc., Belmont, CA.

Seinfeld, J.H. 1986. Atmospheric chemistry and physics of air pollution. Wiley Interscience, New York.

Skeffington. R.A., and T.M. Roberts. 1985. The effects of ozone and acid mist on Scots pine saplings. Oecologia 65:201-206.

Smith, W.H. 1981. Air pollution and forests. Springer-Verlag, New York.

Society of American Foresters. 1984. Acidic deposition and forests. Soc. of Am. For., Bethesda, MD.

Stark, R.W., P.R. Miller, F.W. Cobb, Jr., D.L. Wood, and J.R. Par-meter, Jr. 1968. Photochemical oxidant injury and bark beetle (Coleoptera:Scolytidae) infestation of ponderosa pine I. Incidence of bark beetle infestation in injured trees. Hilgardia 39:121-126

Taylor, G.E., Jr., and R.J. Norby. 1984. The significance of elevated levels of ozone on natural ecosystems of North America. p. 152-175. In S.D. Lee (ed.) Evaluation of the Scientific Basis for Ozone/Oxidant Standard (Trans.). APCA Int. Specialty Conf., Houston, TX. November. Air Pollut. Control Assoc., Pittsburg, PA.

Ulrich, B. 1983. Soil acidity and its relations to acid deposition. p. 27-146. In Ulrich and J. Pankrath (ed.) Effects of accumulation of air nollutants in forest ecosystems. D. Reidel Publishine Co., Hingham, MA.

U.S. Environmental Protection Agency. 1986. Air quality criteria for ozone and other photochemical oxidants: Draft final. EPA-600/8-84-020aF. Environmental Criteria and Assessment Office, Research Triangle Park, NC.

Wachsmuth, E.M., W.K. Murphy, and R.C. Balwin. 1974. Effect of ozone on tracheid development in the limbs of three conifer species. Penn. State Univ., School of Forest Research Briefs 8:4-6.

Wang, D., D.F. Karnosky, and F.H. Bormann. 1986. Effects of ambient ozone on the productivity of Populus tremuloides Michx. grown under field conditions. Can. J. For. Res. 16:47-55.

Webb, C.D., and H.E. Burkhart. 1987. Modeling the effects of air pollution on forest productivity: A sensitivity analysis using PTAEDA. In IUFRO Forest Growth Modelline and Prediction Conference, Minneapolis, MN. 24-28 Aug. Univ. of Minnesota, Minneapolis.

Wilhour, R.G., and G.E. Neely. 1977. Growth response of conifer seedlings to low ozone concentrations. p. 635-645. In USEPA Ecol. Res. Ser. 600/3-77 001b. USEPA, Washington, DC.

Winner, W.E., and C.J. Atkinson. 1986. Absorption of air pollution by plants, and consequences for growth. Trends Ecol. Evolution $1(1): 15-18$. 